\title{
MODE OF FAILURE FOR REINFORCED CONCRETE BEAMS WITH GFRP BARS
}

\author{
Abdelmonem Masmoudi \\ Mechanics, Modelling and Production Laboratory, National School of Engineering of Sfax, University of Sfax, Tunisia \\ e-mail: abdelmonem.masmoudi@enis.rnu.tn \\ Mongi Ben Ouezdou \\ Université de Tunis El Manar, Ecole Nationale d'Ingénieurs de Tunis, LR03ES05 Laboratoire de Génie Civil, Tunis, \\ Tunisia; e-mail: mongi.benouezdou@enit.rnu.tn \\ MOHAMmed HADDAR \\ Mechanics, Modelling and Production Laboratory, National School of Engineering of Sfax, University of Sfax, Tunisia
}

\begin{abstract}
Crack propagation in concrete structures is a very complicated process. An experimental method to predict the stress distribution of a cracked GFRP reinforced concrete flexural beam is presented. The beam subjected to four-point bending is internally reinforced with unidirectional GFRP bars. The aim of this investigation is to study the flexural performance of reinforced concrete members strengthened using GFRP bars. For the flexural tests performed on reinforced concrete beams strengthened with GFRP bars, the ultimate load of the beams strengthened with GFRP was reasonably increased. The mode of failure for beams reinforced with GFRP sections is slightly different compared with the traditional beam. The GFRP reinforced concrete beams fail either by concrete crushing at the compression zone or rupture of the GFRP reinforcement.
\end{abstract}

Keywords: crack propagation, flexural failure, concrete, GFRP bars, stress distribution

\section{Introduction}

Nowadays, the construction industries around the world face a major problem due to corrosion of steel reinforcement. The cost of maintenance of any deteriorated reinforced concrete structures is very expensive. GFRP composite bars are an excellent alternative to steel bars for reinforcing concrete structures in severe environments.

In the last two decades, a number of studies have been carried out to investigate the flexural response of FRP RC beams (Ritchie, 1991; An et al., 1991; Meier et al., 1993). Therefore, flexural failure is a common phenomenon in the case of concrete members. Plain concrete when subjected to flexural loads fails due to crack propagation. In this work, the effects of several further important parameters on the formation and propagation of cracks in concrete are investigated in order to better understand the decisive phenomena of concrete failure under different loading conditions. When $\mathrm{RC}$ beams reach ultimate state with the first two failure modes, the load-carrying capacity of the beams can be easily estimated by applying conventional methods derived using a plane conservation concept.

Experimental studies have been performed to investigate flexural, shear, and failure modes of FRP RC beams (Swamy and Roberts, 1995; Saadatmanesh and Ehsani, 1991; Ritchie et al., 1991; Chajes et al., 1994; Sharif et al., 1994). These studies indicated failure modes that can limit the strengthening effect of FRP retrofitted structures. Recently, four-point bending experiments were performed on FRP strengthened RC beams and compared structural behaviors of beams retrofitted by CFRP (carbon FRP) for flexural strengthening and by GFRP (glass FRP) for shear 
strengthening (Kachalakev and McCurry, 2000). The FRP reinforcement technique for bridge and continuous RC beam applications was investigated by Pham and Al-Mahaidi (2004), Ashour (2004). Both studies used CFRP sheets and observed the failure mechanism of the reinforcement beams. The effect of initial load on the structural behavior of FRP RC beams was also studied by Shin and Lee (2003), Wenwei and Guo (2006), who performed experiments on CFRP RC beams under different sustaining loads. The former study showed that the different sustain load levels have influence on the deflection of the beam. The latter study investigated the effect of initial load on the ultimate strength of the CFRP reinforcement RC beams and a theoretical model was proposed that could predict ultimate strength of the beams under sustaining loads. Shear capacity of FRP reinforcement beams was presented (Bencardino et al., 2007; Jayaprakash et al., 2008). The first study tested CFRP reinforcement RC beams cast without shear reinforcements and observed failure modes in shear. It was concluded that the FRP retrofitted RC beams could avoid shear failure if a carefully designed anchorage system was installed in the beams. Another study (Jayaprakash et al., 2008) showed that bi-directionally attached CFRP strips significantly increased the shear capacity of the RC beams. They also investigated the effect of orientation of CFRP strips on ultimate shear capacity as well as crack propagation. The cracking may significantly affect the moment redistribution in continuous members and more accurate assessment of the influence of FRP reinforcement on the behavior of RC elements (Matos et al., 2012).

\section{Experimental study}

\subsection{Materials}

For all beams ready mixed concrete was used which had been aged for 28 days. $25 \mathrm{MPa}$ concrete grade was used in the manufacturing of these beams using Ordinary Portland cement and crushed aggregates with maximum size of $12 \mathrm{~mm}$. The initial elasticity modulus $E$ was $34 \mathrm{GPa}$ and the measured tensile strength was $2.1 \mathrm{MPa}$. The concrete slump was $100 \mathrm{~mm}$. For the internal GFRP reinforcement 4 bars HA12 (diameter of $12 \mathrm{~mm}$ ) were used. The resistance capacity in shear was provided from $6 \mathrm{~mm}$ diameter shear reinforcement with $120 \mathrm{~mm}$ spacing. Properties of the GFRP and steel bars used in this study and details of beam cross-section are shown in Table 1 (Schock Bauteil GmbH Combar Co., 2006; Aboutaha, 2004). The average ultimate tensile strength was $738 \mathrm{MPa}$ and $400 \mathrm{MPa}$, respectively for GFRP and steel bars. The modulus of elasticity of the tensile reinforcement bars was $60 \mathrm{GPa}$ and $200 \mathrm{GPa}$, respectively for GFRP and steel. The beams were casted with concrete with a cover of $20 \mathrm{~mm}$. For the tensile reinforcement, two $12 \mathrm{~mm}$ diameter bars were used, and for the construction reinforcement, two $8 \mathrm{~mm}$ diameter as the upper reinforcement (Fig. 1).

Table 1. Properties of the GFRP and steel bars used in this study

\begin{tabular}{|l|c|c|}
\hline \multirow{2}{*}{ Type of bar } & Glass & Steel \\
\cline { 2 - 3 } & \multicolumn{2}{|c|}{ Nominal diameter 8 and $12 \mathrm{~mm}$} \\
\hline \hline Tensile modulus of elasticity [GPa] & $60 \pm 1.9$ & $200 \pm 7$ \\
\hline Ultimate tensile strength [MPa] & $738 \pm 22$ & $400 \pm 11$ \\
\hline Density & 2.2 & 7.85 \\
\hline
\end{tabular}

\subsection{Variables of the experiments and beams}

In this investigation, four point flexural tests were performed with the experimental variables being shear strengthening or no shear strengthening in the central zone. In our experimental stu$\mathrm{dy}$, we investigated the influence of the internal reinforcement amount in the composite material 
Table 2. Composition and characteristics of the concrete

\begin{tabular}{|c|c|c|c|c|c|c|}
\hline $\begin{array}{c}\text { Cement I } \\
{\left[\mathrm{kg} / \mathrm{m}^{3}\right]}\end{array}$ & $\begin{array}{c}\text { Water } \\
{\left[\mathrm{kg} / \mathrm{m}^{3}\right]}\end{array}$ & $\begin{array}{c}\text { Sand } \\
{\left[\mathrm{kg} / \mathrm{m}^{3}\right]}\end{array}$ & $\begin{array}{c}\text { Aggregate } \\
(4 / 12) \\
{\left[\mathrm{kg} / \mathrm{m}^{3}\right]}\end{array}$ & $\begin{array}{c}\text { Aggregate } \\
(12 / 20) \\
{\left[\mathrm{kg} / \mathrm{m}^{3}\right]}\end{array}$ & $\begin{array}{c}\text { Compressive } \\
\text { Strength } \\
{[\mathrm{MPa}]}\end{array}$ & $\begin{array}{c}\text { Slump } \\
{[\mathrm{mm}]}\end{array}$ \\
\hline \hline 350 & 207 & 880 & 300 & 650 & 25 & 100 \\
\hline
\end{tabular}

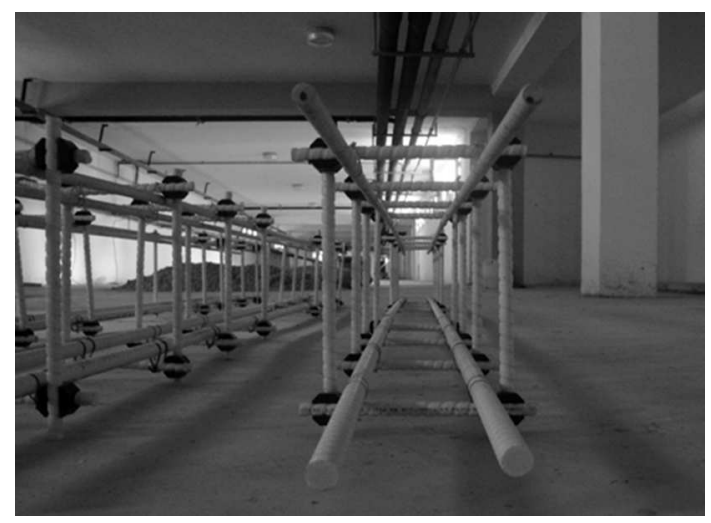

Fig. 1. GFRP bars reinforcement and the beam cross section

on the RC beam response. Two types of beams are studied, with shear GFRP internal reinforcement in central flexural zone in comparison and with steel internal reinforcement. Three beams were reinforced with GFRP bars (designated BG) and three with steel bars (designated BS). All beams were provided with $6 \mathrm{~mm}$ diameter mild stirrup and were designed to fail in flexure. All reinforced concrete beams had spam of $1650 \mathrm{~mm}$ and rectangular cross section $200 \mathrm{~mm} \times 150 \mathrm{~mm}$. The beam cross section was presented in Fig. 2. All beam tests were carried out using a calibrated $500 \mathrm{kN}$ testing machine with displacement-rate control. The data acquisition system was started a few seconds before load application. The displacement rate of loading was kept constant during the tests $(0.005 \mathrm{~mm} / \mathrm{s})$. The beam was mounted on cylindrical contacts which were simply supported. Crack width was controlled step by step during loading. The cracks were marked by a color marker directly on each beam.
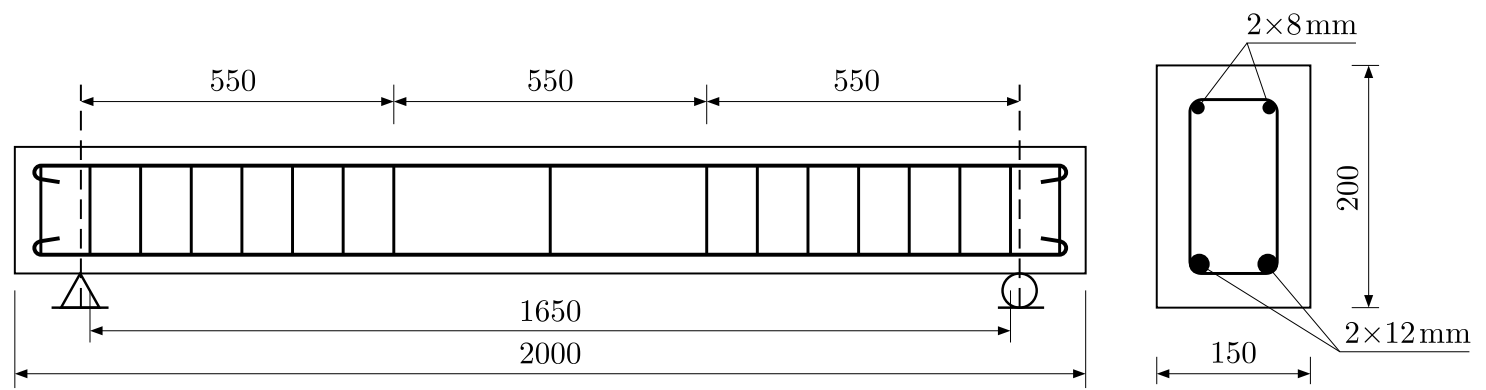

Fig. 2. Beam cross section (all dimensions are in $\mathrm{mm}$ )

The objective of this investigation is to study the mechanisms of flexural failure and stress distribution. The mechanical properties enhancement have been evaluated trough comparison of the strengthened beams mechanical response with the mechanical response of the control beam with steel internal reinforcement. The beam response has been quantified in terms of stress distribution and deflections at the mi-spam. The strain evolution as well as some components of the displacement field has also been monitored. 


\subsection{Arrangement of strain gauges}

Electrical strain deformeter was installed on the flexural plate surface. To obtain an accurate deflection reading, four Linear Variable Differential Transducer (LVDT) were also mounted and one at the mid-span and them connected to a data logger. Since the interface meso-crack propagation pattern was known, the monitoring of the local failure behavior could provide information on the crack-initiation point and on the direction of crack propagation. Electrical strain deformation was installed in order to obtain deflection reading by LVDT (Fig. 3). The detectors were installed on the flexural for both steel and GFRP reinforcement and strain versus load plots were considered. The time "zero" was chosen at the beginning of the load history, or at the moment in which the load was applied. Thus, if the local failure is considered as a "moment" in the load history, the sequence of local failures in the monitored spots can reveal the interface crack initiation point and the crack propagation direction. A schematic diagram of testing arrangement is presented in Fig. 3. We used uni-axial strain gages type CEA-06-250-350 with factor gage $2.08 \pm 0.5 \%$ and resistance $350.0 \pm 0.5 \%$ at $24^{\circ} \mathrm{C}$. Figure 4 shows the strain gages fixed to the GFRP bars and attached to the extensometer pont.
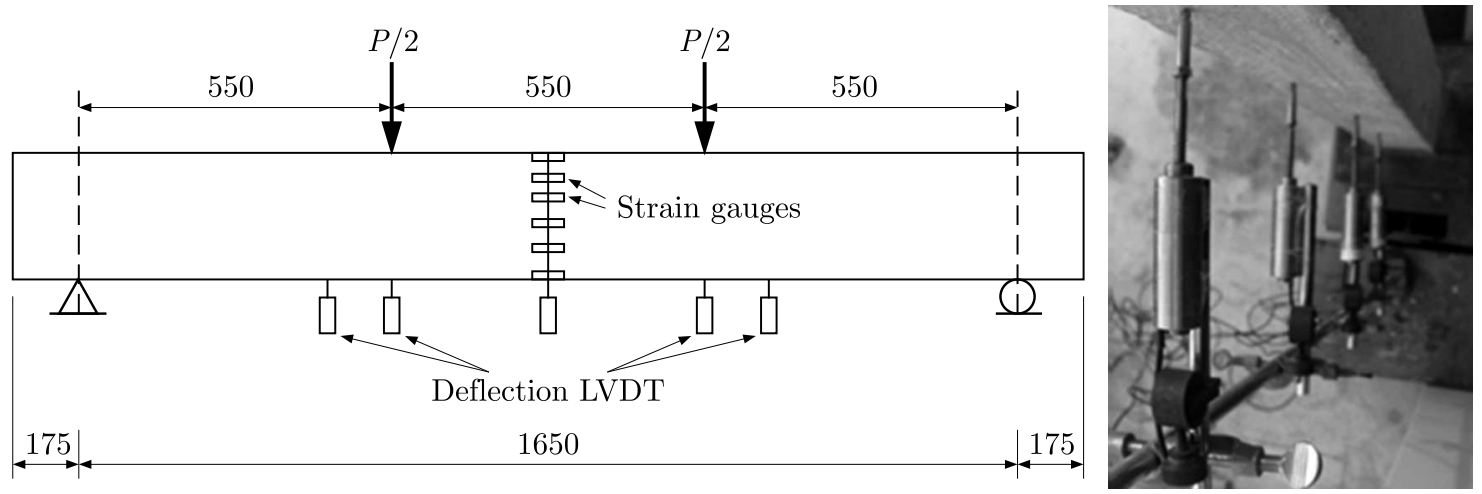

Fig. 3. Schematic diagram of the test set-up
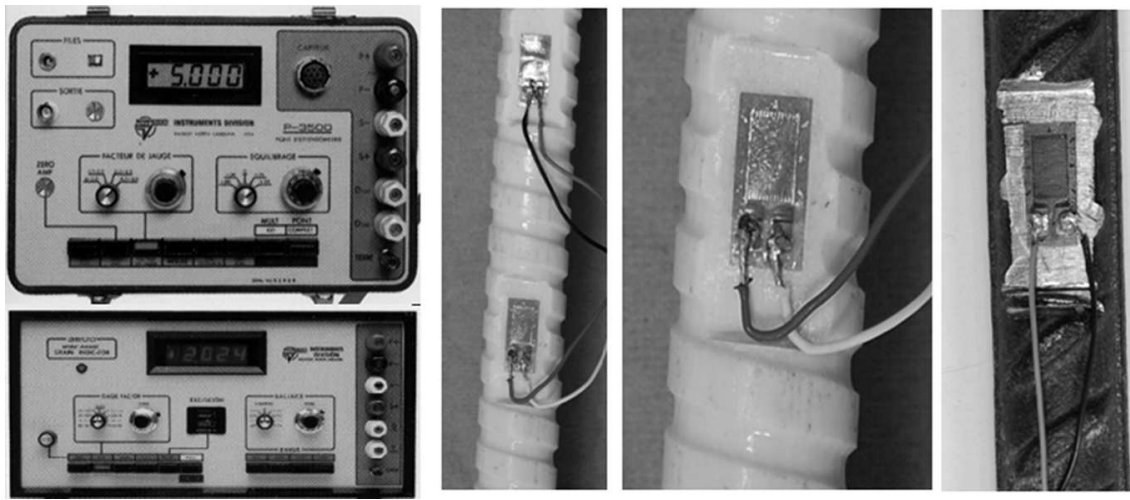

Fig. 4. Gauges for longitudinal deformations

\subsection{Longitudinal modulus of elasticity}

Uniaxial compression tests on cylindrical samples $16 \times 32 \mathrm{~cm}$ were performed to determine the longitudinal modulus of elasticity of concrete used for casting the concrete test beams. The device used showed in Fig. 5 was mounted on a hydraulic press with numerical control. The maximum capacity of this press was $5000 \mathrm{kN}$ with loading speed compression $0.005 \mathrm{~mm} / \mathrm{s}$. The longitudinal elastic modulus of the concrete measured on new specimens was identical to 
the given average of $34122 \mathrm{MPa}$. The evolution of the stress in the concrete according to the deformation is shown in Fig. 6.

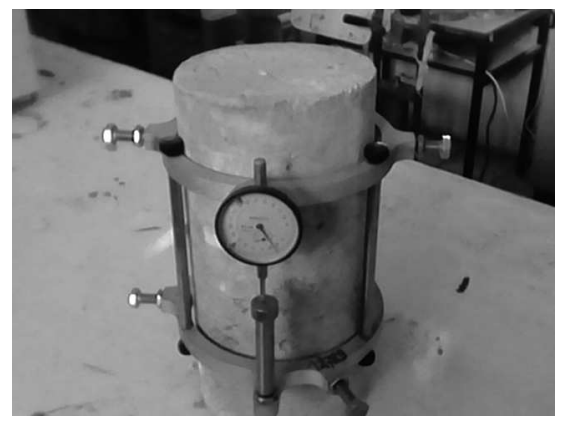

Fig. 5. Test of the longitudinal elasticity modulus

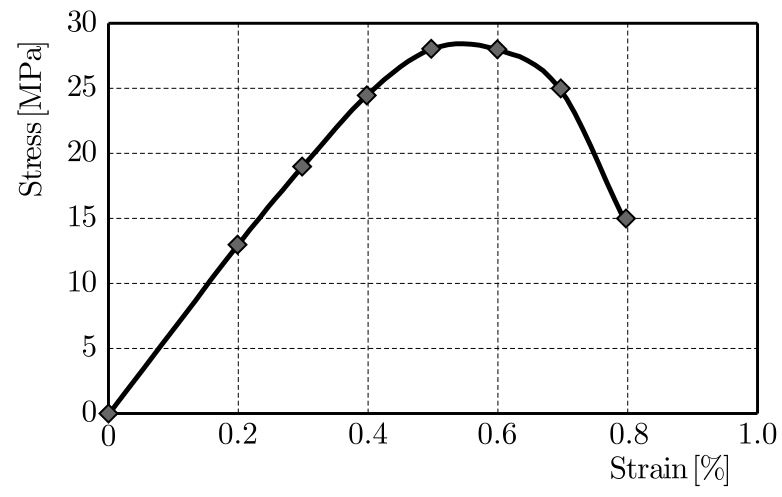

Fig. 6. Evolution of the stress in the concrete vs deformations

\section{Analytical study}

The term of deformation of the steel in tension $\varepsilon_{s 0}$ in the case of uncracked section can be expressed by the following expression

$$
\varepsilon_{s 0}=\frac{Z_{0}}{Z_{1}}\left(\varepsilon_{s 1}+\frac{N_{c}}{A_{s}}\right)
$$

where $Z_{0}$ being the lever arm in the cracked section, $Z_{1}$ - lever arm in the uncracked section, $N_{c}$ - normal tensile stress of concrete.

The deformation of steel in the case of cracked section $\varepsilon_{1}$ can be found from a conventional calculation by the expression

$$
\varepsilon_{s 1}=\frac{d-y}{E_{c} I} M
$$

where $y$ is the position of the neutral axis in the cracked section, $E_{c}$ - modulus of elasticity of the concrete, $I$ - inertia of the cracked section.

The conditions of adhesion between reinforcement bars and concrete are modeled involving a scalar variable mechanical damage $D$ (between 0 and 1 ) given by the following expression

$$
\varepsilon_{c}=\frac{(1-D) \varepsilon_{s 0}}{n}
$$

where $\varepsilon_{c}$ is the deformation of the concrete area, $\varepsilon_{s 0}$ - deformation of bar reinforcement in the uncracked section. 
From equations (3.1) and (3.3) we can express, in the case of the uncracked concrete section, the normal strains in concrete and in the bars. They are as follows

$$
\varepsilon_{c}=\frac{\varepsilon_{s 1}}{\frac{Z_{0}}{Z_{1}}\left(\frac{1}{1-D}+\frac{C}{n A_{s}}\right)} \quad \varepsilon_{s 0}=\frac{\varepsilon_{s 1}}{\frac{Z_{0}}{Z_{1}}\left(1+\frac{(1-D) C}{n A_{s}}\right)}
$$

where $C$ is the contribution of the tensioned concrete surface and $n$ is the equivalence coefficient of concrete steel. We compare the evolution of experimental and theoretical deformations of two reinforcement concrete beams for both BG and BS beams.

\section{Presentation and discussion of the test results}

\subsection{Load-deflection}

The load-deflection behavior of all the beams tested is shown in Fig. 7. Initially, all the beams have relatively the same stiffness. However, once the beam cracked, the stiffness of the GFRP reinforced concrete beam decreased at a faster rate compared with the control beam. This resulted in a larger deflection of the GFRP reinforced concrete beam. The recorded deflections near failure for all beams BG, and BS were, $50 \mathrm{~mm}$, and $32 \mathrm{~mm}$, respectively. It can be seen from Fig. 7 that the stiffness of the beams BG was much lower than that of the beam BS. Again, this was due to the lower elastic modulus of the GFRP sections compared with steel reinforcement. At the same load level, the deflection of beams reinforced with GFRP sections was higher by about 2 to 3 times compared with the beam BS. Thus, at the service load, deflection of the beam reinforced with GFRP sections would be higher than in the beam BS and may not satisfy the design criteria. In addition, a larger deflection would also lead to a wider crack width of the beam.

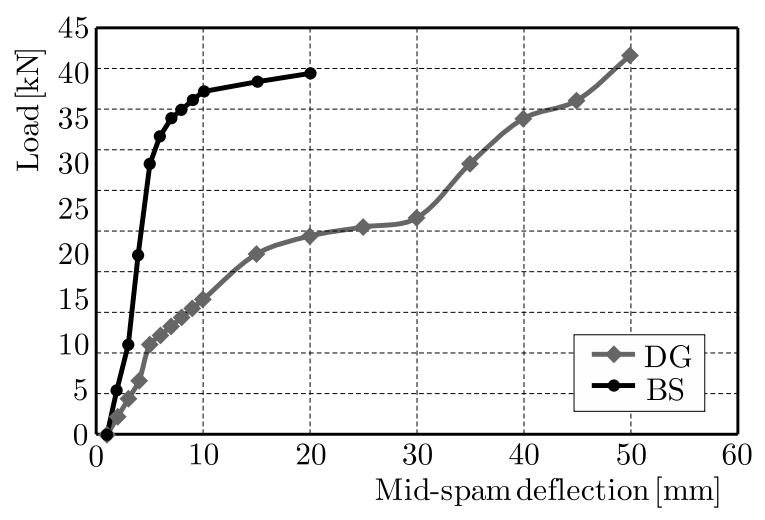

Fig. 7. Load-deflection of all tested beams

\subsection{Load-reinforcement strain}

The tensile strain of the reinforcements was measured and recorded using electrical strain gauges. The load-reinforcement strain behavior of all the beams tested is shown in Fig. 8. It can be seen that the behavior of the load-reinforcement strain was quite similar to the loaddeflection of the beams. An increase in the applied load increased the tensile strain of the reinforcement. From Fig. 8, it can be seen that the bond between concrete and GFRP and steel reinforcements was relatively good. That ensured the transfer of tensile load from concrete to the tensile reinforcements. The experimental results also indicated that the strain of the GFRP reinforcement had linear behavior up to failure. On the other hand, the steel reinforcement 
had a yield point before failure. Thus, in the design process, the aspect of ductile behavior of the beam needs to be taken into account based on the type of tensile reinforcement used. The recorded tensile strain near failure for beams BGI and BS were about 15000 and 5000 micro strains, respectively. On the other hand, the steel reinforcement started to yield at about 3200 micro strains. Obviously, the behavior of the steel reinforcement was elastic-plastic while the GFRP section experienced only elastic behavior. These different strain characteristics of the reinforcement have to be considered when the GFRP section is to be used as concrete reinforcement.

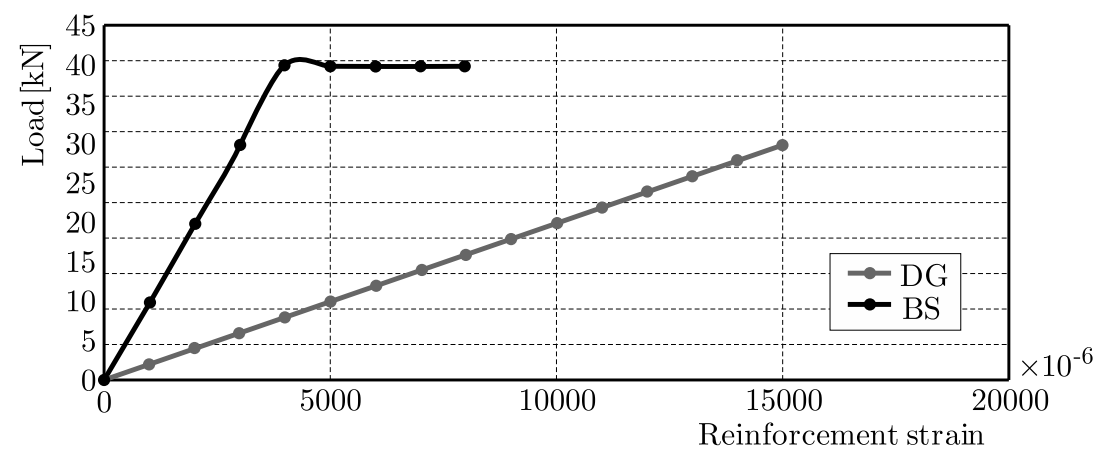

Fig. 8. Load-reinforcement strain of all tested beams

\subsection{Failure mode}

The recorded experimental results show that all the beams failed in flexure by crushing of concrete at the compression zone. The total number of cracks generated for beams BG and BS were 21 and 6, respectively. Hence, the beam with a lower ultimate load due to a lower elastic modulus experienced a lower number of cracks compared with the beam that had a higher load carrying capacity. In addition, the crack spacing for the beam BS was also larger than beam BG and BS. The measured average crack spacing for beams BG and BS were $40 \mathrm{~mm}$ and $130 \mathrm{~mm}$, respectively. It was also observed that the first crack of the GFRP reinforced concrete beams BG was higher by $50 \%$ compared with the beam BS. This result was confirmed by Mias et al. (2015) who found that the use of GFRP bar reinforcement led to an increase in the average crack spacing and crack width.

The first crack load for GFRP reinforced concrete beams was $5 \mathrm{kN}$ while for the beam BS this value was $10 \mathrm{kN}$. A schematic diagram of the cracking of all the beams tested in this study is shown in Fig. 9.

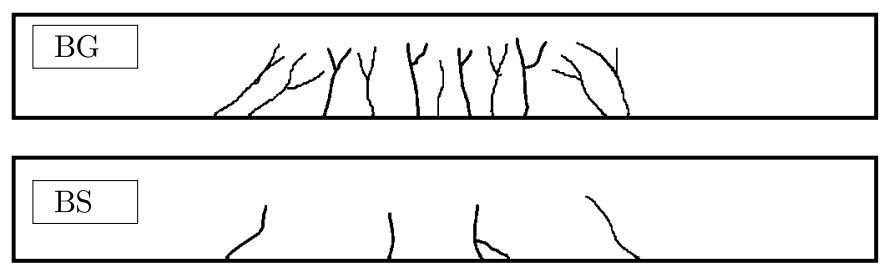

Fig. 9. Diagram of the cracking of beams

Crack propagations were observed during the tests. They are illustrated in Fig. 10. In the control specimen, crack initiation occurred at $2.1 \mathrm{kN}$ around the locations where the load was applied. As the applied load increased, cracks propagated from the beam center and loaded points. When the applied load reached $40.2 \mathrm{kN}$, the reinforcing bar yielded and flexure failure was observed in the specimen. In this load case, the interface crack was initiated at the beam mi-spam and propagated towards the support. At the same time, the data collected from the strain deformeter placed on the composite material showed that the local failure took place 


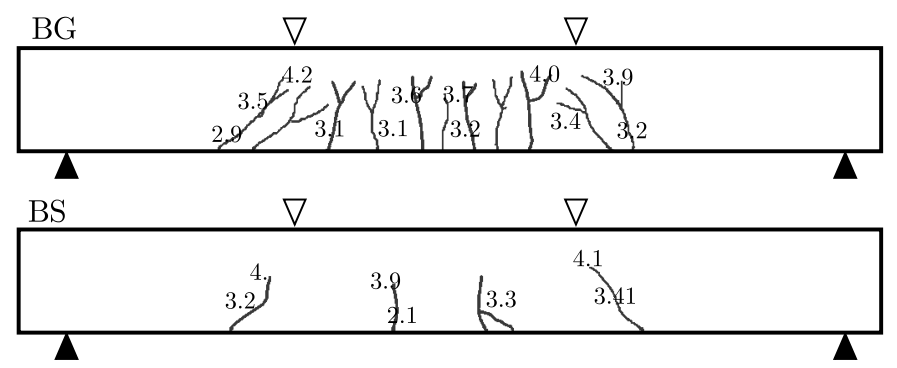

Fig. 10. Level of crack propagation

simultaneously at all monitored regions. Moreover, the simultaneous local failure detected in the composite material coincided with the global failure of the beam and with the "last" local failure on the flexural steel/concrete cover interface. Figures 11 and 12 show that the curve of superior fiber strain $\left(\mathrm{F}_{-\mathrm{sup}^{1}}\right.$ and F-sup ${ }^{2}$ ) decrease above the load of $25 \mathrm{kN}$. This means that the concrete was damaged and plasticized. Contrary to the curve of the inferior fiber strain $\left(\right.$ F-inf ${ }^{1}$ and $\mathrm{F}$-inf $\left.{ }^{2}\right)$, it was still linear. This result confirms the GFRP linear elastic behavior until rupture. The first cracks appeared in the beam at a load of $25 \mathrm{kN}$. There were five active cracks with spacing of $62.4 \mathrm{~mm}$ in the half span of each beam. Crack widths corresponding to the $45 \mathrm{kN}$ load of the beam were respectively $0.325 \mathrm{~mm}, 0.315 \mathrm{~mm}, 0.361,0.324$ and $0.373 \mathrm{~mm}$. We compared the evolution of experimental and theoretical deformations of two reinforcement concrete beams for both types BG and BS. Figures 13 highlights the transfer effort of the reinforcing bar to the concrete in tension. This finding is best seen in the case of the steel beam. An increase in the applied moment generates multiple simultaneous effects. On the one hand, the deterioration of adhesion will continue locally in the portions located between the bending cracks. When degradation is complete, the concrete will not be driven by the reinforcements and mechanically no longer participate. On the other hand, new bending cracks will form in areas closer and closer to the supports. Finally, the area of non-compliance with respect to damage to the adhesive will expand, which means that other sections located between the bending cracks will suffer degradation of adhesion.
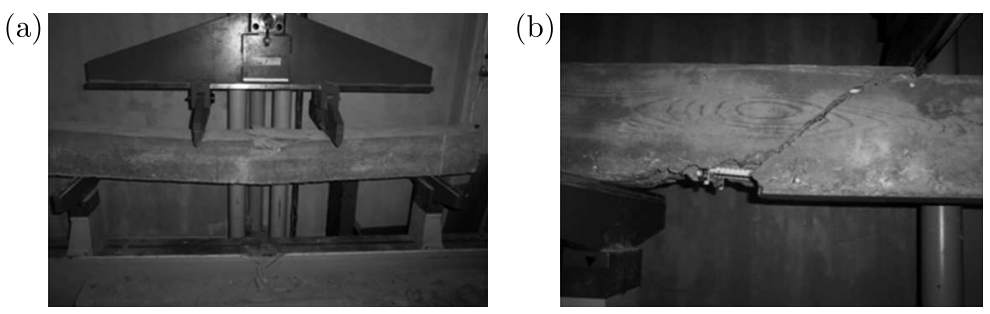

Fig. 11. Beam cracking modes: (a) steel beam, (b) GFRP beam

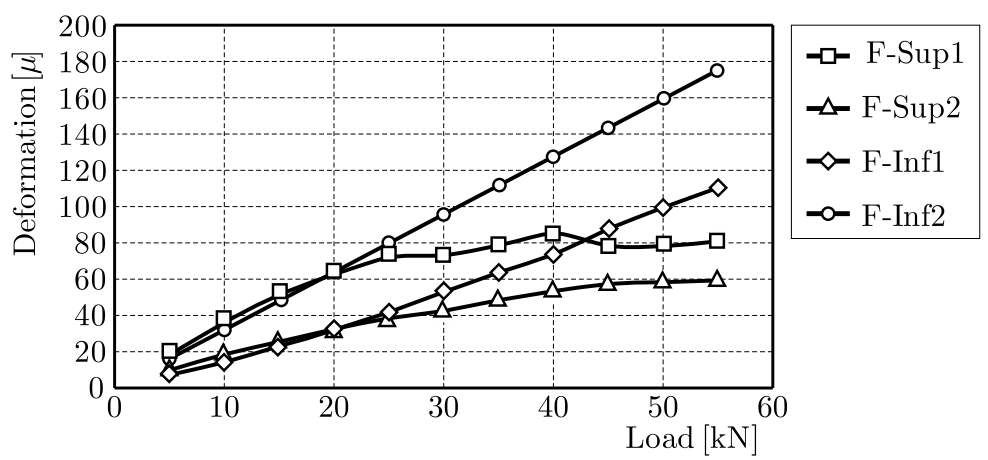

Fig. 12. Strain evolution 


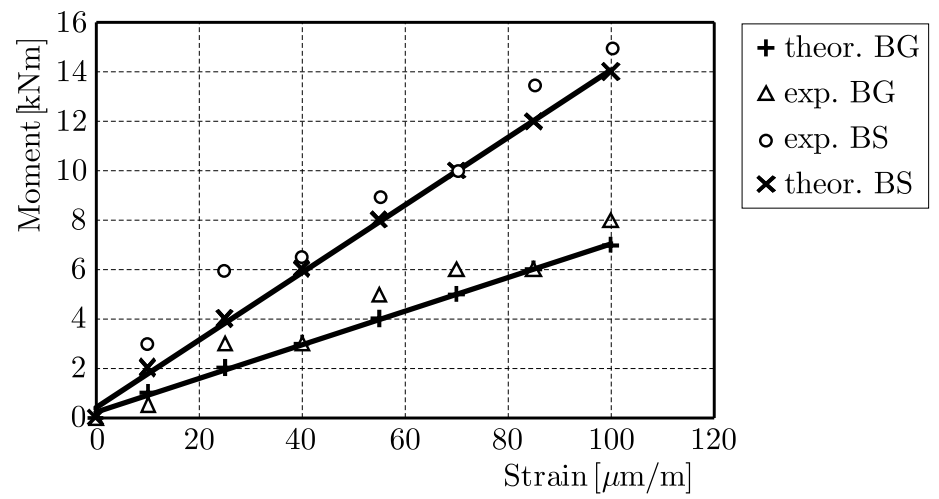

Fig. 13. Evolution of strain in the bar versus moment

The local mechanical behavior has been compared with experimental measurements, the results show good correlations. We can conclude that the local failure mechanism which controls the global failure behavior of the strengthened system takes place in the concrete cover for the beam geometry.

\section{Conclusion}

In this paper, flexural tests were performed for concrete beams reinforced by GFRP bars. The main conclusions drawn from the study are as follows:

- The concrete beam reinforced with GFRP sections experienced a lower load carrying capacity and stiffness compared with the conventional reinforced concrete beam. This was mainly due to the lower elastic modulus of the GFRP section compared with the steel reinforcement.

- The number of cracks for the beam reinforced with GFRP section was higher than in the conventional beam. In addition, the average crack spacing of the GFRP reinforced concrete beam was also larger compared with the control beam.

- The curve of superior fiber strain (F-sup ${ }^{1}$ and F-sup ${ }^{2}$ ) decreased above the load of $25 \mathrm{kN}$. This means the concrete was damaged and plasticized. Contrary to the curve of the inferior fiber strain $\left(\mathrm{F}_{-i n f}{ }^{1}\right.$ and $\mathrm{F}$-inf $\left.{ }^{2}\right)$ it was still linear. This result confirms the GFRP linear elastic behavior until rupture.

- An increase in the applied moment generates the deterioration of adhesion, and new bending cracks are developed.

- The modes of failure for beams reinforced with GFRP sections were slightly different compared with the control beam. The GFRP reinforced concrete beams fail either by concrete crushing at the compression zone or rupture of the GFRP reinforcement. Failure due to rupture of GFRP reinforcement is not recommended since it may result in catastrophic failure of the structure.

\section{Acknowledgments}

The authors would like to thank the manufacturer of the GFRP Combar? (Schöck, Baden-Baden, Germany) for providing GFRP bars and supporting the experimental research. The opinion and analysis presented in this paper are those by the authors.

\section{References}

1. Aboutaha R., 2004, Recommended Design for the GFRP Rebar Combar, Technical Report, Department of Civil and Environmental Engineering, Syracuse University, USA 
2. An W., Saadatmanesh H., Ehsani M.R., 1991, RC beams strengthened with FRP plates. II: Analysis and parametric study, ASCE Journal of Structural Engineering, 117, 11, 3434-3455

3. Ashour A.F., El-Refaie S.A., Garrity S.W., 2004, Flexural strengthening of RC continuous beams using CFRP laminates, Cement and Concrete Composites, 26, 765-775

4. Bencardino F., Spadea G., Swamy R.N., 2007, The problem of shear in RC beams strengthened with CFRP laminates, Construction and Building Materials, 21, 1997-2006

5. Chajes M.J., Thomson Jr T.A., Januszka T.F., Finch JR W.W., 1994, Flexural strengthening of concrete beams using externally bonded composite materials, Construction and Building Materials, 8, 3, 191-201

6. Eurocode 2. "Calcul des structures en béton armé, partie 1.1, règles générales et règles pour les bâtiments", AFNOR, 1992

7. Jayaprakash J., Samad A.A.A., Abbasovich A.A., Ali A.A.A., 2008, Shear capacity of precracked and non-precracked reinforced concrete shear beams with externally bonded bi-directional CFRP strips. Construction and Building Materials, 22, 1148-1165

8. Kachalakev D., McCurry D.D., 2000, Behavior of full-scale reinforced concrete beams retrofitted for shear and flexural with FRP laminates, Composites, Part B, 31, 445-452

9. Matos B., Correia J.R., Castro L.M.S., FrançA P., 2012, Structural response of hyperstatic concrete beams reinforced with GFRP bars: effect of increasing concrete confinement, Composite Structures, 94, 1200-1210

10. Meier U., Deuring M., Meier M., Schwegler G., 1993, Strengthening of structures with advanced composites, [In:] Alternative Materials for Reinforcement and Prestressing of Concrete, J.L. Clarke (Edit.), Blackie Academic and Professional, 153-171

11. Mias C., Torres L., Guadagnini M., Turon A., 2015, Short and long-term cracking behaviour of GFRP reinforced concrete beams, Composites, Part B, 77, 223-231

12. Pham H., Al-Mahaidi R., 2004, Experimental investigation into flexural retrofitting of reinforced concrete bridge beams using FRP composites, Composite Structures, 66, 1/4, 617-625

13. Ritchie P.A., 1991, External reinforcement of concrete beams using fiber reinforced plastics, $A C I$ Structural Journal, 88, 4, 490-496

14. Ritchie P.A., Thomas D.A., Lu L.W., Connelley G.M., 1991, External reinforcement of concrete beams using fiber reinforced plastics, ACI Structural Journal, 88, 4, 490-500

15. SaAdatmanesh H., Ehsani M.R., 1991, RC beams strengthened with FRP plates. I: Experimental study, ASCE Journal of Structural Engineering, 117, 11, 3417-3433

16. Schock Bauteil GmbH Combar Co., 2006, Design Guideline for Concrete Structures Reinforced with Glass Fiber Reinforced Polymer following the Requirements of DIN 1045-1and EC2. Design Guide; Issued Germany

17. Sharif A., Al-Sulaimani G.J., Basunbul I.A., Baluch M.H., Ghaleb B.N., 1994, Strengthening of initially loaded reinforced concrete beams using FRP, ACI Structural Journal, 91, 2, 160-168

18. Shin Y., LeE C., 2003, Flexural behavior of reinforced concrete beams strengthened with CFRP laminates at different levels of sustaining load, ACI Structural Journal, 100, 2, 231-239

19. Swamy R.N., Roberts H., 1995, Structural behavior of externally bonded steel plated RC beams after long-term exposure, Structural Engineering, 73, 16, 255-261

20. Wenwei W., Guo L., 2006, Experimental study and analysis of RC beams strengthened with CFRP laminates under sustaining load, International Journal of Solids and Structures, 43, 1372-1387 